\title{
FRUIT AND VEGETABLE CONSUMPTION IN LATVIAN SCHOOLS WITH VARIOUS TRAINING PROGRAMS ON HEALTHY DIET
}

\author{
Ilze Beitane*, Madara Nevarzavska \\ Department of Nutrition, Faculty of Food Technology, Latvia University of Life Sciences and Technologies, Rigas iela 22, \\ Jelgava, Latvia, e-mail: ilze.beitane@llu.lv
}

\begin{abstract}
Fruit and vegetable recommendations for pupils are similar in the world and in Latvia, that is, at least 5 servings per day, but this is not the case most often. The objective of this study was to assess the contribution of schools with various training programs on healthy diet to raising the fruit and vegetable consumption among pupils. The study involved pupils in grades 6, 9 and 11 from Latvian schools with various training programs for healthy diet in order to analyse students' theoretical knowledge about the role of fruits and vegetables in the diet and their practical experience). Pupils' knowledge and understanding of the consumption and importance of fruit and vegetables in the diet was strongly influenced by gender $(\mathrm{p}<0.05)$, and in some cases by age, while school training program on healthy diet had no significant impact ( $p>0.05$ ). Pupils lacked understanding about the amount of the required fruit and vegetable consumption because one third of the pupils thought that eating 5 servings of fruit and vegetables was unnecessary. The pupils did not understand the essence of a healthy diet because the portion of fried potatoes was indicated as one vegetable portion. Uniformity was observed in the pupils' diet, cucumbers, tomatoes and carrots were the most consumed vegetables, while within fruits - apples and bananas. Improving the pupils' healthy diet program should take into account the different interests of the pupils' gender, age and desire to acquire knowledge in practice.
\end{abstract}

Keywords: fruit, vegetables, consumption, knowledge, pupils

\section{Introduction}

Nutrition has a long-term role in the development, growth and health of the child (Dreher, 2018). Eating fruits and vegetables instead of foods with high fat, salt and sugar content protects children from obesity, diabetes, cardiovascular diseases (Dreher, 2018; Fernandez, Marette, 2017; Tang et al., 2017; Hartley et al., 2013). In turn, it provides a balanced diet use in adult life (Forestell, 2017; Ventura, 2017; Benton, 2004; Cooke et al., 2004). Fruit and vegetable consumption is influenced by many factors such as availability, knowledge, attitudes at home and school, influence of parents and peers, local climate and costs (Sharps et al., 2015; Ventura, Worobey, 2013; Rasmussen et al., 2006; Benton, 2004).

Vegetable and fruit consumption of children is relatively less studied compared to adults, but studies have shown that children in Europe consume $86 \mathrm{~g}$ of vegetables and $141 \mathrm{~g}$ of fruit on average, covering only $6-24 \%$ of the recommended daily consumption of vegetables and fruits (Elmadfa et al., 2009). There was a tendency among the surveyed EU countries that girls consume more fruit and vegetables than boys (Fruit and vegetable .., 2014). The lowest rates of fruit consumption were observed in Greece, Latvia, Lithuania and Sweden, while the lowest vegetable consumption was found in Spain and Estonia (Fruit and vegetable ..., 2014). Research data of Latvian pupils showed that the total fruit consumption - at least once a day - could be attributed only to one fifth of pupils, while vegetable consumption - one vegetable daily - only to one quarter of pupils which was inadequate (Pudule et al., 2015).

Projects aimed at increasing the consumption of fruit and vegetables among pupils that takes place in schools, as it is possible to create, organize various types of activities, such as a traditional training program on nutrition in classrooms, school gardening, cooking (Knai et al., 2006). In order to achieve a better effect, the activities carried out in schools should be diverse and long-lasting. The practical approach is marked as more promising and more effective than classical lessons (Battjes-Fries et al., 2017; DeCosta et al., 2017; Laureati et al., 2014; Knai et al., 2006). In 2007, the European Commission set itself the objective of reducing child obesity, increasing the consumption of fruit and vegetables by launching the School Fruit Program in 2009. The School Fruit Program is a program that provides schools with free fruit and vegetables, thus ensuring fruit and vegetable availability for children. The Norwegian study showed that the School Fruit Program reduced the consumption of unhealthy snacks (Overby et al., 2012).

The program "School Fruit" has been implemented in Latvia since 2010 and by 2018 more than 5,000 tonnes of fruit and vegetables were distributed (Current activity results .....). These data suggest that there should be no problems with sufficient fruit and vegetable consumption among Latvian pupils, but is it true?

The objective of this study was to assess the contribution of schools with various training programs on healthy diet to raising the fruit and vegetable consumption among pupils.

\section{Materials and Methods}

The participants of the study were $6^{\text {th }}, 9^{\text {th }}$ and $11^{\text {th }}$ grade pupils whose theoretical knowledge and practical approach to the consumption of fruit and vegetables was collected through questionnaires. The pupils represented schools with a diverse training program on healthy diet: schools with a classical training program (SchCTP) and schools involved in the "Healthy School Network" (SchHSN) (Table 1). The schools involved in 
the study were located in Riga; two of the schools were with a classical training program and three schools were involved in the "Healthy School Network". Gender distribution was 163 boys and 167 girls.

Table 1

Number of pupils involved in the study by type of a school and a class

\begin{tabular}{|c|c|c|c|}
\hline \multirow{2}{*}{ Class } & \multirow{2}{*}{ Total } & \multicolumn{2}{|c|}{ Schools } \\
\hline & & SchCTP & SchHSN \\
\hline 6 & 135 & 61 & 74 \\
\hline 9 & 149 & 72 & 77 \\
\hline 11 & 46 & 35 & 11 \\
\hline Total & 330 & 168 & 162 \\
\hline
\end{tabular}

SchHSN - schools involved in the "Healthy School Network"

The questionnaire consisted of 15 questions, where questions were open and multiple choice. It was anonymous, indicating only the gender and age of the pupil. Pupils completed the questionnaire at school, without limiting time. The questionnaire included questions about the pupil's knowledge of healthy eating, the necessary amount of fruit and vegetable consumption, as well as the issues that characterize the pupil's personal opinion and experience of daily consumption of fruit and vegetables. Survey results were processed using the SPSS statistical program, where each research participant was assigned an identification code. The result was considered statistically significant if $\mathrm{p}$ was less than 0.05 .

\section{Results and Discussion}

Pupils' knowledge of a healthy diet was superficial, which revealed that pupils knew fruit and vegetables contain minerals and vitamins, but had no idea of the importance of fibre. In addition, one portion of fried potatoes was indicated as a single portion of vegetables, because the pupils did not know that potatoes were not counted as vegetables due to the high starch content. Girls would be interested to learn more about healthy eating, while $63 \%$ of boys would not like to do so, but admitted that it would be useful for their athletic growth. While assessing pupils' views on the need for five portions of fruit and vegetables every day, it became clear that it is not emphasized in schools nor explained at all (Figures 1 and 2).

The answer "unnecessary" was most often given by pupils from schools with classical training program $(40 \%)$, boys $(38 \%)$ and $11^{\text {th }}$ grade pupils $(43 \%)$. An interesting relationship was observed between the results: the older the pupil, the more often the answer "unnecessary" was mentioned. This could be explained by the fact that the $11^{\text {th }}$ grade pupils define and make their own menus, have their own opinion and cannot be longer influenced by parents or teachers.

Gender differences in this study confirmed the literature data that boys use less fruit and vegetables than girls (Fruit and vegetable ..., 2014).

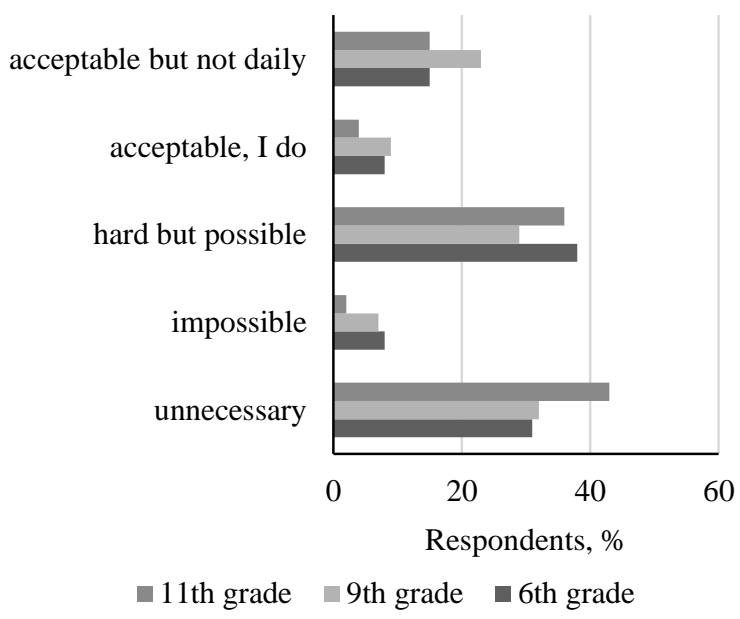

Figure 1. Pupils' opinion on the consumption of 5 portions of fruit and vegetables per day according to pupils' age, \%

$28 \%$ of pupils from schools involved in the "Healthy School Network" indicated that 5 servings of fruit and vegetables per day are not required. It is difficult to explain why such a large number of pupils are not aware of it, but it could be related to the passive learning method - lectures that do not give the required result. Several studies show that a practical approach provides better results than the passive lectures (Battjes-Fries et al., 2017; DeCosta et al., 2017; Laureati et al., 2014; Knai et al., 2006).

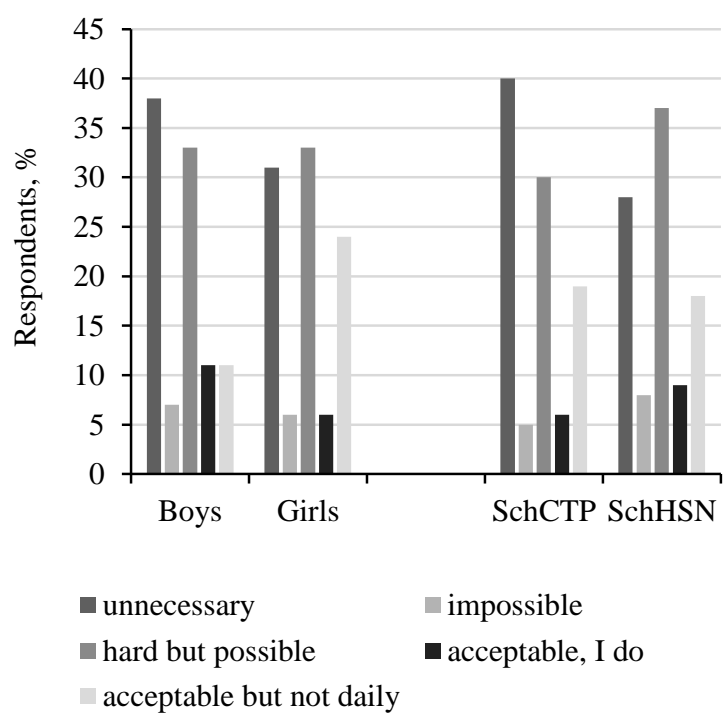

Figure 2. Pupils' views on the consumption of 5 portions of fruit and vegetables per day by gender and depending on the school, \%

SchCTP - schools with a classical training program, SchHSN - schools involved in the "Healthy School Network"

When asking pupils what they think is the optimal fruit and vegetable consumption per day, the most popular answers were 1 or 2 portions (Table 2 and 3 ).

The answers could be explained by the actual daily consumption of fruit and vegetables by pupils. It is 
known that the consumption of fruit and vegetables among pupils is lower than the recommendation (Yngve et al., 2005). It is a positive fact that only a small number of the surveyed pupils believed that there is no need to eat fruit and vegetables at all. However, there were also pupils who thought that fruit and vegetables could be eaten without any restrictions. This shows that pupils do not understand that a healthy diet should also be used in reasonable quantities.

Table 2

Pupils' views on the required amount of fruits and vegetables according to pupils' gender, \%

\begin{tabular}{lcccc}
\hline \multirow{2}{*}{ Amount } & \multicolumn{2}{c}{ Fruit } & \multicolumn{2}{c}{ Vegetables } \\
\cline { 2 - 5 } & Boys & Girls & Boys & Girls \\
\hline 1 portion & 32 & 34 & 47 & 45 \\
2 portions & 31 & 43 & 21 & 32 \\
3 portions & 6 & 5 & 4 & 8 \\
The more & 29 & 17 & 23 & 14 \\
the better & & & & \\
No need & 2 & 1 & 5 & 1 \\
\hline
\end{tabular}

When analysing data between schools with a diverse training program on healthy diet, no significant differences ( $p>0.05)$ were found in the pupils' responses (Table 3).

Table 3

Pupils' views on the required quantities of fruit and vegetables depending on the school, \%

\begin{tabular}{lcccc}
\hline \multirow{2}{*}{ Amount } & \multicolumn{2}{c}{ Fruits } & \multicolumn{2}{c}{ Vegetables } \\
\cline { 2 - 5 } & SchCTP & SchHSN & SchCTP & SchHSN \\
\hline 1 portion & 35 & 31 & 48 & 44 \\
2 portions & 41 & 33 & 27 & 27 \\
3 portions & 4 & 7 & 6 & 6 \\
The more & 19 & 27 & 17 & 19 \\
the better & & & & \\
No need & 1 & 2 & 2 & 4 \\
\hline
\end{tabular}

SchCTP - schools with a classical training program,

SchHSN - schools involved in the "Healthy School Network"

The results of the study showed that, according to the pupils, it is necessary to consume more fruit than vegetables. On the issue of commonly used fruit and vegetables, pupils first named apples $(70.8 \%)$, then bananas $(53.2 \%)$, oranges $(23.1 \%)$, kiwis $(11.4 \%)$. Less than $10 \%$ of pupils also mentioned pears, mandarins, grapes, mango, strawberries, and pineapples. The most popular vegetables among pupils were cucumbers $(46.5 \%)$, tomatoes $(44.9 \%)$, carrots $(29.8 \%)$, potatoes $(27.7 \%)$, and cabbage $(10.2 \%)$. Less than $10 \%$ of pupils also mentioned lettuce, broccoli, paprika, avocado, and beets. Vegetables, which were most often mentioned as tasteless, were broccoli (13.9\%), pumpkin (11.8\%), and eggplant $(10.1 \%)$, while for fruit it were kiwis $(6.7 \%)$ and mango $(6.7 \%)$.

The data showed that the training program on healthy diet in school has no significant impact on pupils' knowledge and understanding of fruit and vegetable consumption and nutritional importance (Table 4). It is known that schools involved in the "Healthy School Network" teach pupils more about healthy eating, including fruit and vegetable consumption, but the results showed no significant differences $(p>0.05)$. This showed that passive learning in the form of lectures did not produce the desired result. The significant difference was identified between the genders $(p<0.05)$. Girls showed greater interest in learning the basics of healthy eating, had a better knowledge of fruit and vegetable consumption while boys were less interested. The results showed that the training method on healthy diet should be based on the needs of each gender. The boys mentioned that dietary training would be much more attractive if nutrition topics were linked to sport, how to build a healthy menu to promote athletic achievements. Furthermore, pupils indicated that they wanted to learn more through practice rather than theory.

Table 4

Differences between pupils' knowledge, fruit and vegetable consumption and other characteristics

\begin{tabular}{lccc}
\hline Evaluated indicators & School & Gender & Grade \\
\hline $\begin{array}{l}\text { Pupils' desire to learn } \\
\text { more about healthy }\end{array}$ & $\mathrm{p}>0.05$ & $\mathrm{p}<0.05$ & $\mathrm{p}>0.05$ \\
$\begin{array}{l}\text { eating } \\
\text { Pupils' desire to learn } \\
\text { more about cooking }\end{array}$ & $\mathrm{p}>0.05$ & $\mathrm{p}<0.05$ & $\mathrm{p}<0.05$ \\
$\begin{array}{l}\text { Necessary amount of } \\
\text { fruit in daily diet }\end{array}$ & $\mathrm{p}>0.05$ & $\mathrm{p}<0.05$ & $\mathrm{p}<0.05$ \\
$\begin{array}{l}\text { Necessary amount of } \\
\text { vegetables in daily diet }\end{array}$ & $\mathrm{p}>0.05$ & $\mathrm{p}<0.05$ & $\mathrm{p}<0.05$ \\
$\begin{array}{l}\text { Pupils' views on 5 } \\
\text { portions of fruit and } \\
\text { vegetables per day }\end{array}$ & $\mathrm{p}>0.05$ & $\mathrm{p}<0.05$ & $\mathrm{p}>0.05$ \\
$\begin{array}{l}\text { Pupils' desire to learn } \\
\text { about fruit and vegetable } \\
\text { growing and their use in } \\
\text { nutrition }\end{array}$ & $\mathrm{p}>0.05$ & $\mathrm{p}>0.05$ & $\mathrm{p}>0.05$ \\
\hline
\end{tabular}

While assessing the impact of age, it was concluded that older pupils had a better knowledge and understanding of the consumption of fruit and vegetables and their role in the diet. Families have an important role to play in the choice of nutrition for younger pupils, as they make the child's dietary habits and understanding of a healthy diet.

\section{Conclusions}

Pupils' knowledge and understanding of the consumption and importance of fruit and vegetables in the diet was strongly influenced by gender $(\mathrm{p}<0.05)$, while school training program on healthy diet had no significant impact $(\mathrm{p}>0.05)$. Pupils lacked understanding about the amount of the required fruit and vegetable consumption, in addition it was insufficient and uniform. The most commonly used vegetables were cucumbers, tomatoes and carrots, while the most popular fruit were apples and bananas. Pupils did not know that potatoes are not counted within vegetables due to their high starch content. Improving the pupils' healthy diet program should take into account the different interests of the pupils' sex, age and desire to acquire knowledge in practice. 


\section{References}

1. Battjes-Fries M.C.E., Haveman-Nies A., Zeinstra G.Z., van Dongen E.J.I., Meester H.J., van den Top-Pullen R., van't Veer P., de Graaf K. (2017) Effectiveness of taste lessons with and without additional experiential learning activities on children's willingness to taste vegetables. Appetite, Vol. 109, p. 201-208.

2. Benton D. (2004) Role of parents in the determination of the food preferences of children and the development of obesity. International Journal of Obesity, Vol. 28, p. $858-869$.

3. Cooke L.J., Wardle J., Gibson E.L., Sapochnik M., Sheiham A, Lawson M. (2004) Demographic, familial and trait predictors of fruit and vegetable consumption by pre-school children. Public Health Nutrition, Vol. 7(2), p. 295-302.

4. Current activity results of the programmes "School milk" and "School fruit". [accessed on 03.02.2019.]. Available at: http://piensaugliskolai.lv/en/about/current-activityresults-of-the-programmes-school-milk-and-school-fruit/

5. DeCosta P., Moller P., Frost M.B., Olsen A. (2017) Changing children's eating behaviour - A review of experimental Research. Appetite, Vol. 113(1), p. 327-357.

6. Dreher M.L. (2018) Whole fruits and fruit fiber emerging health effects. Nutrition, Vol. 10(12), p. 1833.

7. Elmadfa I., Meyer A., Nowak V., Hasenegger V., Putz P., Verstraeten R., Remaut-DeWinter A. A. M., Kolsteren P., Dostálová J., Dlouhý P., Trolle E., Fagt S., Biltoft-Jensen A.P., Mathiessen J., Groth M.V., Kambek L., Gluškova N. (2009) European Nutrition and Health Report. DTU Library [accessed on 31.01.2019.]. Available at: http://orbit.dtu.dk/files/84414155/enhrii_book.pdf

8. Fernandez M.A., Marette A. (2017) Potential health benefits of combining yoghurt and fruits based on their probiotic and prebiotic properties. Advances in Nutrition, Vol. 8(1), p. 155-164.

9. Forestell C.A. (2017) Flavor perception and preference development in human infants. Annals of Nutrition \& Metabolism, Vol. 70(3), p. 17-25.

10. Fruit and vegetable consumption statistics 2014. Eurostat Statistics Explained. [accessed on 31.01.2019.]. Available at: https://ec.europa.eu/eurostat/statisticsexplained/index.php?title=Fruit_and_vegetable_consump tion_statistics\#Consumption_of_fruit_and_vegetables

11. Hartley L., Igbinedion E., Holmes J., Flowers N., Thorogood M., Clarke A., Stranges S., Hooper L., Rees K. (2013) Increased consumption of fruit and vegetables for the primary prevention of cardiovascular diseases. Cochrane Database of Systematic Reviews, Issue 6. Art. No.: CD009874.

12. Knai C., Pomerleau J., Lock K., McKee M. (2006) Getting children to eat more fruit and vegetables: a systematic review. Preventive Medicine, Vol. 42(2), p. 85-95.

13. Laureati M., Bergamaschi V., Pagliarini E. (2014) School based interventation with children. Peer-modeling, reward and repeated exposure reduce food neophabia and increase liking of fruits and vegetables. Appetite, Vol. 83, p. 26-32.

14. Overby N.C., Klepp K.I., Bere E. (2012) Introduction of a school fruit program is associated with reduced frequency of consumption of unhealthy snacks. The American Journal of Clinical Nutrition, Vol. 96, p.1100-1103.

15. Pudule I., Velika B., Grinberga D., Gobina I., Villerusa A. (2015) Health behaviour in school-aged children Latvia. The Centre for Disease Prevention and Control of Latvia. [accessed on 31.01.2019.]. Available at: https://www.spkc.gov.lv/upload/Petijumi\%20un\%20zinoj umi/HBSC/hbsc_2013_2014_aptaujas_rez.pdf

16. Rasmussen M., Krolner R., Klepp K.I., Lytle L., Brug J., Bere E., Due P. (2006) Determinants of fruit and vegetable consumption among children and adolescents: a review of literature. Part I: quantitative studies. International Journal of Behavioral Nutrition and Physical Activity, Vol. 3(22), p. 1-19.

17. Sharps M., Higgs S., Blissett J., Nouwen A., Chechlacz M., Allen H.A., Robinson E. (2015) Examining evidence for behavioural mimicry of parental eating by adolescent females. A observational study. Appetite, Vol. 89, p. 56-61.

18. Tang G.Y., Meng X., Li Y., Zhao C.N., Liu Q., Li H.B. (2017) Effects of vegetables on cardiovascular diseases and related mechanisms. Nutrition, Vol. 9(8), p. 857.

19. Ventura A.K. (2017) Does breastfeeding shape food preferences? Links to obesity. Annals of Nutrition \& Metabolism, Vol. 70(3), p. 8-15.

20. Ventura A.K., Worobey J. (2013) Early influences on the development of food preferences. Current Biology, Vol. 23(9), R 401-408.

21. Yngve A., Wolf A., Poortvliet E., Elmadfa I., Brug J., Ehrenblad B., Franchini B., Haraldsdottir J., Krolner R., Maes L., Perez-Rodrigo C., Sjostrom M., Thorsdottir I., Klepp K.I. (2005) Fruit and vegetable intake in a sample of 11-year-old children in 9 European countries: the pro children cross-sectional survey. Annals of Nutrition and Metabolism, Vol.49, p. 236-245. 